\title{
Impact of Shared Bus on Campus Travel and Space Optimization Based on Activity Travel Behavior
}

\author{
Qiong Chen $\mathbb{D}^{1}{ }^{1}$ Hong Zhang $\mathbb{D}^{1},{ }^{1}$ Jianbiao Wang, ${ }^{2}$ Hongyu Ye, ${ }^{1}$ Zhaoming Chu, ${ }^{3}$ \\ Bixia Lou, ${ }^{2}$ and Dawei $\mathrm{Li}^{2}$ \\ ${ }^{1}$ School of Architecture, Southeast University, Nanjing 210000, China \\ ${ }^{2}$ School of Transportation, Southeast University, Nanjing 210000, China \\ ${ }^{3}$ Research Institute for Road Safety of MPS, Beijing 100062, China
}

Correspondence should be addressed to Hong Zhang; zhangseu@aliyun.com

Received 1 June 2021; Revised 3 July 2021; Accepted 14 July 2021; Published 31 July 2021

Academic Editor: Shaopeng Zhong

Copyright (c) 2021 Qiong Chen et al. This is an open access article distributed under the Creative Commons Attribution License, which permits unrestricted use, distribution, and reproduction in any medium, provided the original work is properly cited.

Based on the travel analysis of students in the Jiulonghu campus, this paper constructs a small-scale shared bus in the campus, explores the impact of shared traffic on campus travel, promotes the optimization design of campus space environment, and creates a more comfortable and convenient travel space. In order to overcome the shortcomings of the traditional trip-based research, this paper analyzes travel behavior from the perspective of activity-based travel concept framework, considering more activities and travel information. At the same time, in order to improve the richness of information, the explicit preference survey (RP) and the declarative preference survey (SP), which are added to the bus sharing customized travel platform, are used to collect data of personal attributes and travel diary. Firstly, based on the ArcGIS platform, this paper constructs the activity travel path generation tool, dynamic activity density distribution tool, and spatiotemporal path clustering tool and comprehensively analyzes the activity travel mode from the aspects of time distribution, spatial distribution, and category characteristics. Secondly, based on the travel activities, the location selection model (S-MNL) considering the heterogeneity of SP and RP data sources and the activity duration planning model (Cox regression), considering the nonnormal distribution of activity duration are established to analyze the impact of shared bus on students' travel distance, travel time, and travel frequency. Finally, according to the analysis of modeling results, the impact of shared traffic on campus travel is analyzed, and the optimal design scheme of campus space is given. This paper uses the survey method based on declarative preference SP and the survey method based on explicit preference (RP) to get the actual and hypothetical travel response of travelers, which improves the data richness.

\section{Introduction}

Shared mobility reduces traffic congestion, reduces greenhouse gas emissions, promotes social welfare, and has a great impact on urban space environment. Centralized cities provide convenient travel and transfer, and improve the share rate of public transport; mixed land use can induce the change in people's travel mode [1]. However, rapid and extensive urban space design has brought about negative effects. With the deepening of shared transportation to social life, it brings great challenges to the planning of transportation system. Therefore, in order to solve the traffic problems and improve the travel satisfaction of travelers, it is essential to consider the impact of shared traffic on the built space environment [2].

Travel and traffic are two-way influences. First of all, the research on the impact of space environment on travel includes: Liu et al. studied travelers' preference for the surrounding environment of subway station, and think that pedestrians prefer the travel environment with floor height less than six floors and street lamp spacing between $15 \mathrm{~m}$ and $30 \mathrm{~m}$ [3]. In addition, improving station accessibility will improve travel quality and destination attractiveness, and induce more trips [4]. The research of shared travel should be put in specific activities, based on the activities to study travel behavior, in order to pay attention to more travel 
information, such as activity location, activity duration, activity trip times in a day, and so on. Many studies have also confirmed the advantages of activity-based travel model in travel behavior analysis $[1,5]$.

Secondly, most of the current studies focus on the impact of the existing built environment on travel behavior. Because of the lack of data, researchers cannot observe and compare the responses of the same traveler in different built environment. Therefore, the survey method based on declarative preference (SP) provides a good remedy. Declarative preference survey is a survey method based on assumptions, which can get travelers' travel responses to different spatial environments and provide more information for behavior research. However, in the SP survey design, there are several points to pay attention to: (1) the built-up space should have a certain impact on the activity travel; (2) the design should be comparable, and small changes should be made according to the existing environment; if the changes are too large, it will lead to no comparison; and (3) the activities of travelers need to be more regular, so as to reduce the interference of random factors on the survey.

As a large and densely populated area, road traffic is an important part of the campus traffic system. How to develop a small-scale shared bus circulation system within the campus to help the campus environment play a better role under the premise of ensuring the daily travel needs of teachers and students is a research worthy topic. Therefore, in view of the above conditions, this study identified the survey objects as university campuses and students. At the same time, as Mesquita said, colleges and universities are innovative groups, so they will try to experience the optimized space environment more actively, and can be used as potential experimental sites for urban planning to bring guiding significance for a wider range of research in the future [6].

To sum up, this paper will take the students in the Jiulonghu campus of Southeast University as the survey object, and using the combination of the revealed preference (RP) survey based on the actual travel and the declarative preference (SP) survey based on different assumptions, and based on the activity travel behavior analysis method, more accurately and comprehensively analyze the impact of shared traffic on students' travel behavior, and make some suggestions to optimize the space environment to improve travel satisfaction and convenience.

\section{Literature Review}

2.1. Activity-Based Travel Model. As a new traffic travel research model, the activity-based travel model has been gradually adopted by researchers in recent years. The activity-based travel model also innovates the traditional four-stage traffic method. Vo et al. considered that under the interaction of family members, based on the activity-based travel behavior, traffic flow is allocated to the network [7]. Li et al. take the shared car travel into account in the activity-based dynamic user equilibrium model, allocate traffic to the super network, and explore the changes of network traffic under different policies [8]. Based on mobile big data records, Bassolas et al. take it as the input data of the activity-based travel demand model to study the impact of traffic demand management policies, and prove the advantages of the activity-based travel demand model [9]. Activity-based travel model considers more information from the perspective of travel chain. For example, Nahmias-Biran and Shiftan have included activities and trips in the research model, and constructed composite indicators to evaluate the fairness of infrastructure enjoyed by different social groups [10]. Baqueri et al. extended the model to study the limitation of the size of the study area, which is the defect of the activity-based model, and considered the activity trips outside the study area in the trip chain [11]. In addition, in the analysis of activity trip and influencing factors, Zimmerman et al. use the hybrid recursive logit model to comprehensively consider the activity, time, place, trip, and other aspects [12] and improve the recursive logit model proposed by Fosgerau et al. to release the limitation of IIA, making the model more effective in explanation and prediction [13]. In order to explore the complexity of individual activity travel decision-making dimensions, Fu Xuemei conducted a joint modeling analysis on the five decision-making dimensions of activity travel, and confirmed that there is an interaction between different decision-making dimensions.

\subsection{Impact of Built Environment on Transportation.} Many studies have studied the relationship between built environment and travel behavior, and confirmed that built environment has a great impact on travel behavior. Based on the demand data of public bicycle card, Liu and Lin explored the impact of built environment around public bicycle stations, such as land commercialization rate and connectivity to leisure places, on the spatial and temporal distribution of bicycle travel [14]. Similarly, Chevalier et al. studied the acceptance of bicycles in different university campuses in Shanghai based on a questionnaire survey [15]. In addition, Lin Yunnan analyzed the impact of built environment around rail transit stations on cycling with the help of ofo data in Shenzhen. For cars, Ding and Cao used a multilevel cross classification model to study the impact of built environment near home address and work place, such as bus station density and work density, on car ownership intention [16]. In addition, Huang et al. constructed a spatial weighted model to study the built environment and traffic accidents, which showed that factors such as intersection density was related to traffic accidents [17]. For the walking mode (connecting to subway on foot), Cheng et al. used 0.5 logit in the walking mode of the elderly. The model and the risk proportion model, respectively, study the impact of the built environment and the travel frequency and time of the elderly, as well as the research on the elderly [18]. Relying on the survey data of physical activity of Nanjing residents, Jiang Yupei and others select the walking activities of the elderly as the research topic to explore the impact of built environment and provide corresponding planning strategies.

\subsection{Analysis and Research on Campus-Related Travel} Behavior. Different from the ordinary junior and senior high school students, the class time of college students is relatively not fixed, and at the same time, they have great freedom on campus. Therefore, college students can be regarded as a social 
group with complex and unique travel behavior. There are many literatures on the travel behavior of the university campus. After collecting the data of public bicycle use in several schools, Kutela and Teng studied the influence of campus characteristics on the use of public bicycle on campus through the mixed effect negative binomial regression model. The results show that the size of the school, the distance from downtown, and other factors have a significant impact on the daily use of public bicycles on campus [19]. Similarly, Chevalier et al. took five schools in Shanghai as the research objects and discussed the impact of built environment on bike sharing in campus [15]. Filipovitch and Frimpong Boamah proposed an optimization algorithm to optimize the campus parking cost, to ensure that the parking management will not lose money under this cost, and to minimize the contradiction between supply and demand [20]. In addition, the travel behavior of bike sharing in the university campus has also been widely studied and analyzed. After a week-long follow-up survey of college students in suburban areas, Limond et al. conducted a classification study on different types of students, discussed travel mode, travel distance, travel time in detail, and pointed out that there was a strong correlation between college students' travel behavior [21]. Aiming at the simplest and most basic mode of transportation in the university campus, Meng Dongsheng and others took the Beichen campus of Hebei University of Technology as an example to objectively analyze the current situation of its pedestrian road, found the problems existing in the actual use process through the current situation investigation, and put forward development suggestions for the construction of pedestrian environment in the new campus of the university in the future. Moreover, there is a lot of literature about campus travel behavior and mode choice. In the aspect of mode selection, predecessors have made many achievements. Alar et al. studied the transportation choices of individuals on the campus of Ohio State University in Columbus. A webbased survey was conducted to understand the travel patterns of campus communities and to make recommendations to reduce single person vehicle travel in the campus [22]. Mahlawat et al. investigate the tourism behavior of students at Texas A\&M University. After careful examination of the collected data, descriptive statistical tests were conducted to better understand the different characteristics of passengers under different modes, and to determine the variables included in the mode selection model. The results show that travel time, travel cost, income, expenses, family type, school hours, gender, and race are the important factors of students' choice mode [23].

The first part is introduction. Firstly, according to the investigation and analysis and data search, this paper expounds the background and significance of the research; secondly, it summarizes the domestic and foreign research on the activity-based travel model, and the impact of built environment on traffic travel and campus travel behavior. The second part: SP and RP survey design and data collection. This paper explores the idea of customized travel service platform for unmanned bus. The data of travel diary and personal attributes in SP's imaginary space environment and RP's real space environment were collected, and the differences between weekend and nonweekend were considered. The third part: Based on the analysis of temporal and spatial path of time geography. With the help of the ArcGIS platform, the secondary development is carried out through the model builder. The optimized design of campus space can utilize the batch processing and visual analysis results of the survey data. The fourth part: the establishment and result analysis of activity travel behavior model. This paper expounds the decision-making process of activities in one day, highlights the dynamic and internal relationship of decision-making, and distinguishes it from the study of a single trip. It helps to explore the influencing factors of activity travel behavior. According to the results, the campus space is analyzed and optimization suggestions are put forward. The fifth part: summary and prospect. First of all, this paper summarizes the research problems and gives the innovation of this paper, and then discusses the shortcomings and improvements, in order to prepare for further research.

\section{Methodology}

The survey site of this study is the Jiulonghu campus of Southeast University, as shown in Figure 1. It is located in the Jiangning District of the Jiangsu Province and has been put into use since 2006. In the campus, the library is located in the center. The living areas of Tao Yuan, Mei Yuan, and Ju Yuan are located in the northeast, southeast, and southwest, respectively. Each living area is equipped with playground, shops, canteens, and other necessary facilities, with a total area of more than $3700 \mathrm{mu}$. It takes 20-25 minutes to cross the whole campus. Therefore, this campus is very suitable for the study of small-scale activity travel behavior.

In the data collection of shared traffic behavior analysis, most of the studies use declarative preference (SP) survey or explicit preference (RP) survey to collect data. More and more researches combine the investigation based on explicit preference and declarative preference to make up for their respective shortcomings, such as the preference for the content and form of road information signs. Zhao et al. used the investigation method of combining explicit preference and narrative preference to obtain data and conduct research on it, so as to improve the acceptance efficiency of road users to information signs. Therefore, this paper also uses the combination of narrative preference and explicit preference to investigate the daily travel of college students on campus.

In the design of space environment under the assumption of SP, in view of the effectiveness of the investigation and the particularity of colleges and universities, this paper puts forward two SP design principles:

(1) The proposed built space should be in line with the campus atmosphere and have a certain impact on the activity travel.

(2) The space design should be comparable, that is to say, small changes should be made according to the existing environment. If the changes are too large, it will bring inconvenience in comparison.

Based on the above principles, combined with the current popular concept of sharing economy and customized travel, this paper proposes a customized travel service 


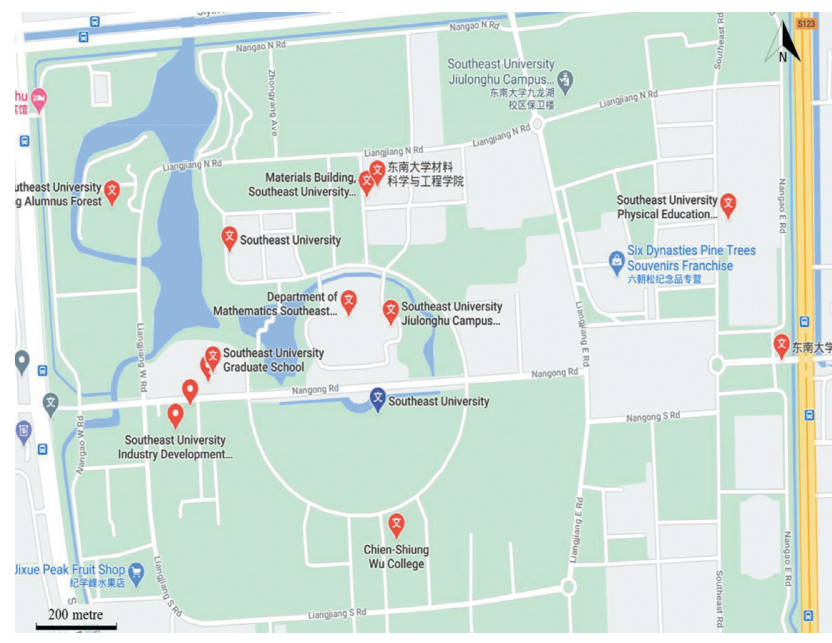

FIGURE 1: Southeast University Kowloon lake campus plan.

platform for shared unmanned bus according to the prototype of the existing driverless bus in the Jiulonghu campus of Southeast University (Figure 2) and proposes to put such customized travel platforms near the north gate, near the library, and near the gymnasium, as the unmanned bus is located in three SP scenarios in different locations (Figure 3). After arriving at the platform, students can customize their next trip and take the unmanned bus to any place on the campus. As shown in Figures 2 and 3, this paper will collect data based on the three kinds of space environment (SP survey) and the existing space environment (RP survey).

3.1. Structure of SP and RPQuestionnaires. The questionnaire is mainly divided into two parts. The first part comprises the personal attributes of the interviewees, and the specific contents are shown in Table 1 . It mainly includes reading type, gender, GPA ranking, and other factors.

The second part is the travel diary survey under RP's existing space environment and SP's scenario. The content structure of the survey is shown in Figure 4. The daily travel diary consists of multiple trips, as shown in Figure 4. Each trip is composed of destination selection, travel time, and travel mode.

The structure of the travel diary survey under different SP space environments is similar to that under RP existing space environment, which is also composed of different travel segments, with each segment being composed of a travel destination. But, the difference is that due to the addition of the shared bus customization platform, there are more bus customized travel point options and more customized travel mode options in the choice of destination, as shown in Figure 5.

3.2. Statistical Description of Personal Attributes. Table 2 shows the statistical description of social attribute variables of respondents. From the table, it can be seen that most of the respondents are undergraduates, accounting for about $85 \%$ of the student population. The proportion of science and engineering accounts for less than $80 \%$ of the subjects, which is generally in line with the discipline setting of Southeast University. The distribution of gender and whether it is an only child is more uniform. The dormitory located in the Taoyuan living area accounts for more than $60 \%$, the living area of Meiyuan accounts for more than $30 \%$, while the orange garden accounts for only $5 \%$ of the total area. The reason for this proportion is that the Taoyuan living area is the most populated living area in the three living areas, and secondly, the sample size of nonundergraduate type students (master, doctor) located in the orange garden living area is too small. In addition, most people (70\%) are within the range of 1000-2000 yuan in terms of living expenses.

3.3. Analysis on the Setting Effect of Customized Bus Stops. In order to preliminarily understand whether the shared traffic under SP assumption will have an impact on travel attributes, this section selects two dimensions of space (the total distance of a day) and time (the total time of going out activities in a day) to explore. At the same time, it will also focus on the differences between weekends and nonweekends. Tables 3 and 4 are the one-way ANOVA tests for different locations of customized bus stops on weekends and nonweekends, respectively. The inspection contents include the total travel distance and the total travel time. It can be seen from Table 3 as to whether a shared bus trip point set up on the weekend has a significant impact on the travel distance, which will increase the travel distance by about $1000 \mathrm{~m}$, and the most significant impact is set in front of the library. This phenomenon is mainly caused by two parts: first, because travelers need to walk to the bus platform to use this mode of travel, it will increase the travel distance; on the other hand, due to the convenience and ease of customized bus service, it will increase the acceptable travel distance of travelers.

But, the difference is that on weekdays, bus stops near the stadium and North Gate do not significantly affect travel distance. In other words, it is far less effective to operate customized bus stops on weekdays than on weekends. But interestingly, when bus stops are set near the library, the impact on travel distance is still significant. Part of this change should be due to the fact that on weekdays, the bus stops near the library will attract travelers who come to and go to the classroom to change their destination to the library. Because most of the respondents come from Tao Yuan and Mei Yuan living areas, the distance between the library and the teaching building is considerable. Compared with walking or cycling, bus customized travel is obviously easier. At the same time, the attributes of library and classroom destinations are very similar. Therefore, setting the bus point in front of the library, even on weekdays, still has a significant impact. Therefore, the operation of customized bus travel platform can be carried out in different periods. For example, increase the operation time on weekends and reduce the operation time on weekdays. At the same time, priority should be given to setting in front of the library.

According to Table 4, whether or not bus points are set on weekends or working days has no significant impact on 


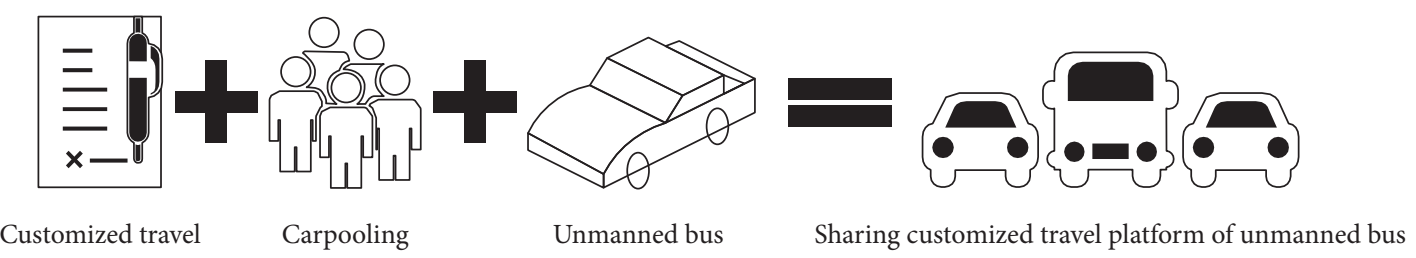

Figure 2: Design of customized travel platform for unmanned bus.

the total time of one-day-out activities. This conclusion is in line with expectations. Because the increase of bus points increases the travel acceptable distance of travelers, the total length of activities within a day is determined by their own activity needs, such as how long they study every day and how long it takes to eat. These habits cannot be changed simply by sharing bus points. Therefore, some places such as art exhibition hall and vocational training center can be added to change the internal needs of students, increase the daily time of students going out, and improve the diversity of life in the school.

\section{Model}

4.1. S-MNL Model considering Heterogeneity of SP and RP Data Sources. Multivariate discrete choice model (MNL), as a kind of generalized extreme value distribution choice model, is widely used because of its concise and efficient form. The formula is as follows:

$$
P_{\text {in }}=\frac{\exp \left(\mu \beta_{i} x_{i}\right)}{\sum_{j \in A_{n}} \exp \left(\mu \beta_{i} x_{i}\right)}, \quad i \in A_{n},
$$

where $P_{\text {in }}$ is the probability of traveler $n$ choosing $I$ activity location, $A_{n}$ is the travel scheme selection set of traveler $n, J$ is the elements in a set of $A_{n}, \mu$ is the the scale coefficient of $H$-model, $x_{i}$ is the explanatory variable, and $\beta_{i}$ is the parameter to be estimated.

Generally speaking, for the sake of the identifiability of the model, the scale coefficient $(\mu)$ of the model is set to 1 to estimate $\beta_{i}$ directly. However, due to the fact that the survey data include the data of SP and RP under different survey methods and different data sources, the variance distribution of the unobservable part is also different, that is, the scale coefficients ( $\mu \mathrm{sp}, \mu \mathrm{RP}$ ) of the unobservable items under the survey of SP and RP will be different, as follows:

Distribution of unobservable items of SP data source:

$$
\varepsilon n S P \sim \operatorname{logistic}(0, \mu s) .
$$

Distribution of unobservable items of RP data source:

$$
\varepsilon n \mathrm{RP} \sim \operatorname{logistic}(0, \mu \mathrm{RP}) .
$$

At this time, it is unreasonable to default the scale system of SP and RP data sources to 1, so the scale heterogeneity of the model needs to be considered [24]. In the specific operation, in order to ensure the identifiability of the model, this study fixed the scale parameter $\mu 1$ of RP data source to 1 , and solved the relative scale parameter $\mu 2$ of SP data source relative to RP data source. Therefore, the maximum likelihood estimation of S-MNL model considering scale heterogeneity is as follows:

$$
L=\sum_{n} \sum_{j \in A_{n}} f_{i n} \ln \left(\frac{\exp \left(\mu^{k} \beta_{i} x_{i}\right)}{\sum_{j \in A_{n}} \exp \left(\mu^{k} \beta_{i} x_{i}\right)}\right),
$$

where $f_{\text {in }}$ is the the frequency that traveler $n$ chooses $J$ to be observed, $\mu k-\mu 1$ is the traveler $n$ from RP survey data source, and $\mu 2$ is the from SP survey data source.

In terms of the travel mode, shared unmanned bus travel has a significant positive impact on library and other leisure choices, whether on weekends or weekdays (Table 5). It should be pointed out that the previous ANOVA test shows (Table 3) that the increase of bus platform on weekdays will not significantly increase the travel distance of travelers, which seems to contradict the conclusion that the travel mode of shared bus on weekdays will attract travelers to the library and other categories (subway stations) with longer distance ANOVA. The test is aimed at the total travel distance, not a single trip. Due to the tight schedule on weekdays, when travelers are attracted to a distant library or subway station, they will compress the distance at other times. For example, when they originally planned to go to a restaurant far away at noon or in the evening, they would consider the time to eat nearby. As a result, the total travel distance does not change, and it is a phenomenon of significant increase.

As for the influence of the specific location of bus spots, on the weekend, for the choice of leisure (gymnasium, subway station, activity center), the setting near the gymnasium has a significant positive impact. On the one hand, setting it near the gymnasium will attract more people to the gymnasium; on the other hand, the gymnasium is close to the east gate of the school, which is convenient for bus booking from the school gate to the subway station. Therefore, compared with the north gate, the setting near the gymnasium can promote the diversity of activities. For the choice of library, the setting of shared bus near the library on weekends will have a significant positive impact on the way to the library. It is generally believed that the distance from the library is an important factor to limit the library's round trip. However, after increasing the number of bus points, students can take the shared bus in front of the library to return to the dormitory area, which is more convenient and efficient. At the same time, as mentioned above, the orange garden canteen will attract some people to dine on weekends. At this time, adding a bus in front of the library will make it more convenient for students to go to the orange garden canteen, so it also increases the willingness to go to the 


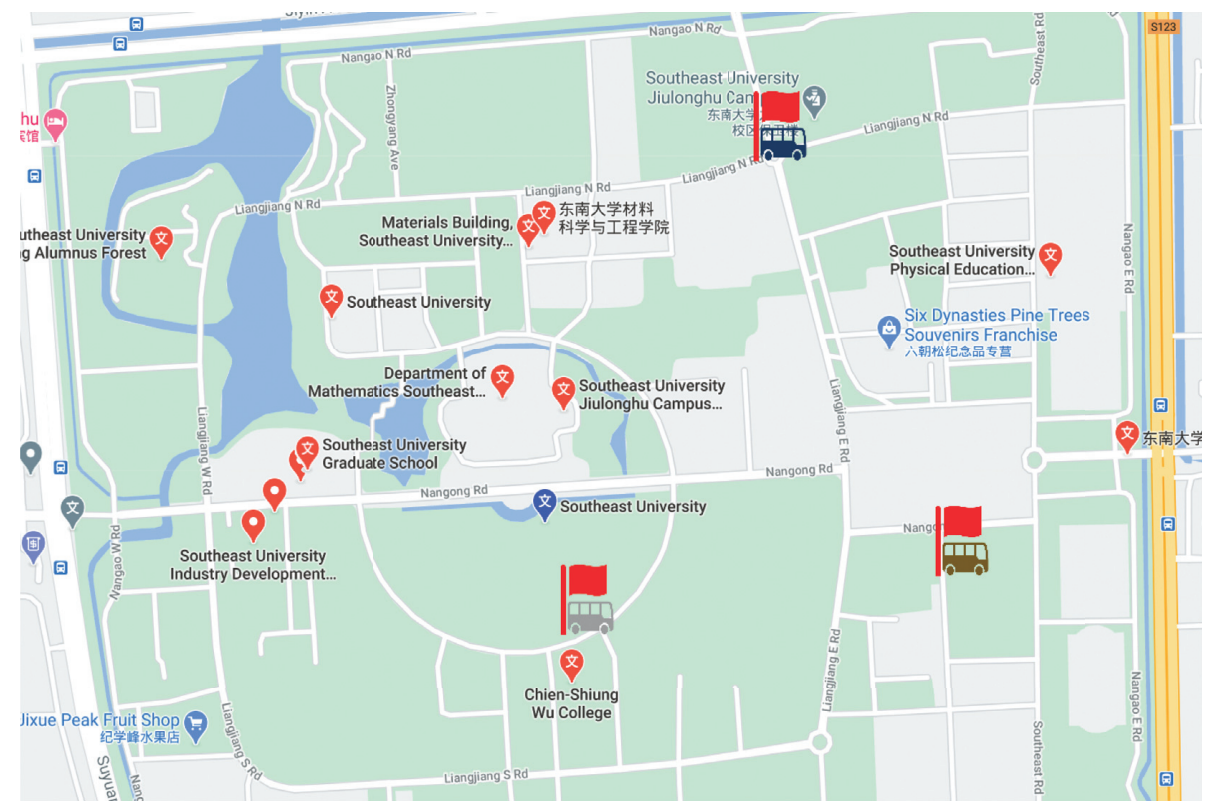

SP scenario (1) North Gate
SP scenario (2) Library
SP scenario (3) Gymnasium

FIgURE 3: Location of shared bus platform in three SP survey scenarios.

library to a certain extent. In addition, the addition of bus stops near the library on weekends will have an impact on travel. Another reason is that the school bus cannot reach the library. In the campus, motor vehicles are forbidden near the library, which is a good measure to ensure the safety of pedestrians. But, it virtually increases the travel time. Generally, it takes about 15-20 minutes to walk from the dormitory to the library. On the other hand, it is suggested to set up a special library bus to ensure the safety of students. In addition, it can alleviate the pressure of sharing buses and play a complementary role.

\subsection{Cox Regression Model considering Distribution Charac-} teristics of Activity Duration. Cox regression model is a common method of multivariate survival analysis, which was proposed by Cox himself in 1972. Cox regression is a semi-parametric model method, which considers the influence of different factors on the survival time. It can analyze the data with truncated survival time, and is widely used in medicine. In recent years, Cox regression has been gradually used as a research method in the field of transportation [18].

The common expressions of Cox are as follows:

$$
h(t \mid X)=h 0(t) \exp (\mathrm{XT} \beta)
$$

where $h(t \mid X)$ is the the probability of instantaneous departure after staying at the active point for $t, h 0(t)$ is the baseline risk rate, $X$ is the explanatory variable, and $\beta$ is the parameters to be estimated.
In addition, risk ratio (RR) will be used in Cox regression. That is, when the $X$ variable increases by one unit, the probability of leaving from the activity site increases by a multiple. The specific expression of RR index is as follows:

$$
R R=\frac{h\left(t \mid x_{2}\right)}{h\left(t \mid x_{1}\right)}=\frac{h_{0}(t) \exp \left(x_{2} \beta_{x}\right)}{h_{0}(t) \exp \left(x_{1} \beta_{x}\right)}=\exp \left(\beta_{x}\left(x_{2}-x_{1}\right)\right),
$$

where $x_{1}, x_{2}$ are the different values of variable $x$ and $\beta x$ is the variable $x$ parameter estimate.

As for travel-related variables, travel time has a positive impact on the activity duration of the location on weekdays. That is to say, when the travel time increases, the activity duration of the location will also increase. On the contrary, on weekends, the activity duration of the traveler is not sensitive to the travel time. On weekdays, students are short of time and need to do a lot of things. Therefore, if they travel to a place for a long time, travelers tend to stay at this place for a long time to increase the benefits of this place. But on weekends, students have plenty of time, so they are not very sensitive to the travel time. Therefore, the idea of walking campus can be advocated and encouraged. Everyone should try their best to walk on weekends to exercise. In response, the appearance of the sidewalk has to be improved, a special jogging or pedestrian road connecting all parts of the campus has to be established, and if the distance is too far, students can be encouraged to use the walking- $x$ mode, that is, students can walk for a certain distance, and then use other means of transportation, such as sharing buses or bicycles, so that they do not give up the idea of walking because of the distance. 
TABLe 1: A survey of personal social attributes.

\begin{tabular}{|c|c|c|}
\hline Variable name & Description & Variable horizontal value \\
\hline Reading type & Current educational background of respondents & $\begin{array}{l}\text { (1) Undergraduate } \\
\text { (2) Nonundergraduates }\end{array}$ \\
\hline Subject type & Subject type of respondents & $\begin{array}{l}\text { (1) Science and engineering } \\
\text { (2) Liberal arts }\end{array}$ \\
\hline Gender & Gender of respondents & $\begin{array}{l}\text { (1) Male } \\
\text { (2) Female } \\
\end{array}$ \\
\hline Family & Family type of respondents & $\begin{array}{l}\text { (1) Town } \\
\text { (2) Rural }\end{array}$ \\
\hline Dormitory & Specific location of respondents' dormitory & $\begin{array}{l}\text { (1) Tao Yuan } \\
\text { (2) Mei Yuan } \\
\text { (3) Ju Yuan }\end{array}$ \\
\hline Schoolwork burden & Respondents' schoolwork burden & $\begin{array}{l}\text { (1) Very heavy } \\
\text { (2) Heavy } \\
\text { (3) Commonly } \\
\text { (4) Relaxed } \\
\text { (5) Very relaxed }\end{array}$ \\
\hline GPA ranking & Respondents' ranking in class & $\begin{array}{l}\text { (1) } 20 \% \\
\text { (2) } 20 \%-50 \% \\
\text { (3) } 50 \%-80 \% \\
\text { (4) } 80 \% \\
\end{array}$ \\
\hline Living expenses & Monthly living expenses of respondents & $\begin{array}{l}\text { (1) }<1000 \\
\text { (2) } 1000-1500 \\
\text { (3) } 1500-2000 \\
(4)>2000\end{array}$ \\
\hline Only child or not & Is the interviewee an only child & $\begin{array}{l}\text { (1) Yes } \\
\text { (2) No }\end{array}$ \\
\hline Do you have a boyfriend/girlfriend & Whether the interviewee has a boyfriend/girlfriend & $\begin{array}{l}\text { (1) Yes } \\
\text { (2) No }\end{array}$ \\
\hline
\end{tabular}

As expected, the remaining time budget has a negative impact on the duration of the activity, because with less and less remaining time, travelers need to make more careful trade-offs, so less time is allocated to the activity. On weekends, different locations also affect the length of activities. As shown in Table 6, the length of stay in the library is significantly lower than that in the classroom. It is speculated that the reason for this phenomenon is the difference between the functions of the library and the classroom itself. Although the library can support self-study, its main function is to lend materials, and the time spent in this kind of self-study is far shorter than that in the classroom for a long time. In addition, even if they will study in the library, the distance from the library to the location of the next activity will be much farther than that from the classroom. Waiting, such as to get back to the dormitory, to go to Tao Yuan, Mei Yuan canteen for dinner, travelers will spent more time on the road, thus reducing the time of stay in the library.

\section{Activity Travel Behavior Analysis}

In 1970, Hägerstrand put forward the concept of time geography [25], which is a method to study travelers' activities and trips under the condition of time and space constraints. In view of the advantages of time space path in describing travelers' activity travel behavior, this paper will analyze the daily travel diary of travelers with the help of time space path, excavate the spatial-temporal characteristics of travelers' activity travel behavior, compare the impact of different sharing traffic schemes on travel, and finally optimize the campus space environment according to the results.

In this study, with the help of the model builder block in ArcGIS platform, the secondary development of the analysis tool is carried out, and the travel diary is processed and analyzed in batches.

5.1. Space Time Path Analysis. In this study, weekend and nonweekend are discussed separately, and specific to different space environment designs, namely, RP's existing space environment and SP's space environment. Figure 6 shows the visualization of space-time path under the RP survey on weekends and working days. The starting time coordinate in the figure is set at 6:00 in the morning. After 6:00, the students begin to have activities. After that, starting from A3 and B3, the activity patterns of weekends and weekdays began to change. Weekend (A3) began to become diverse, and the distribution of activity duration was more uniform. However, on weekdays, there are two intensive activity areas, B3 and B4, which respectively represent different centralized time periods for returning to the dormitory. Some people choose to go back to the dormitory directly after dining at the end of the course, as shown in B3, and this period is densely distributed. The main reason is that the end time of the course is $5: 30$, 


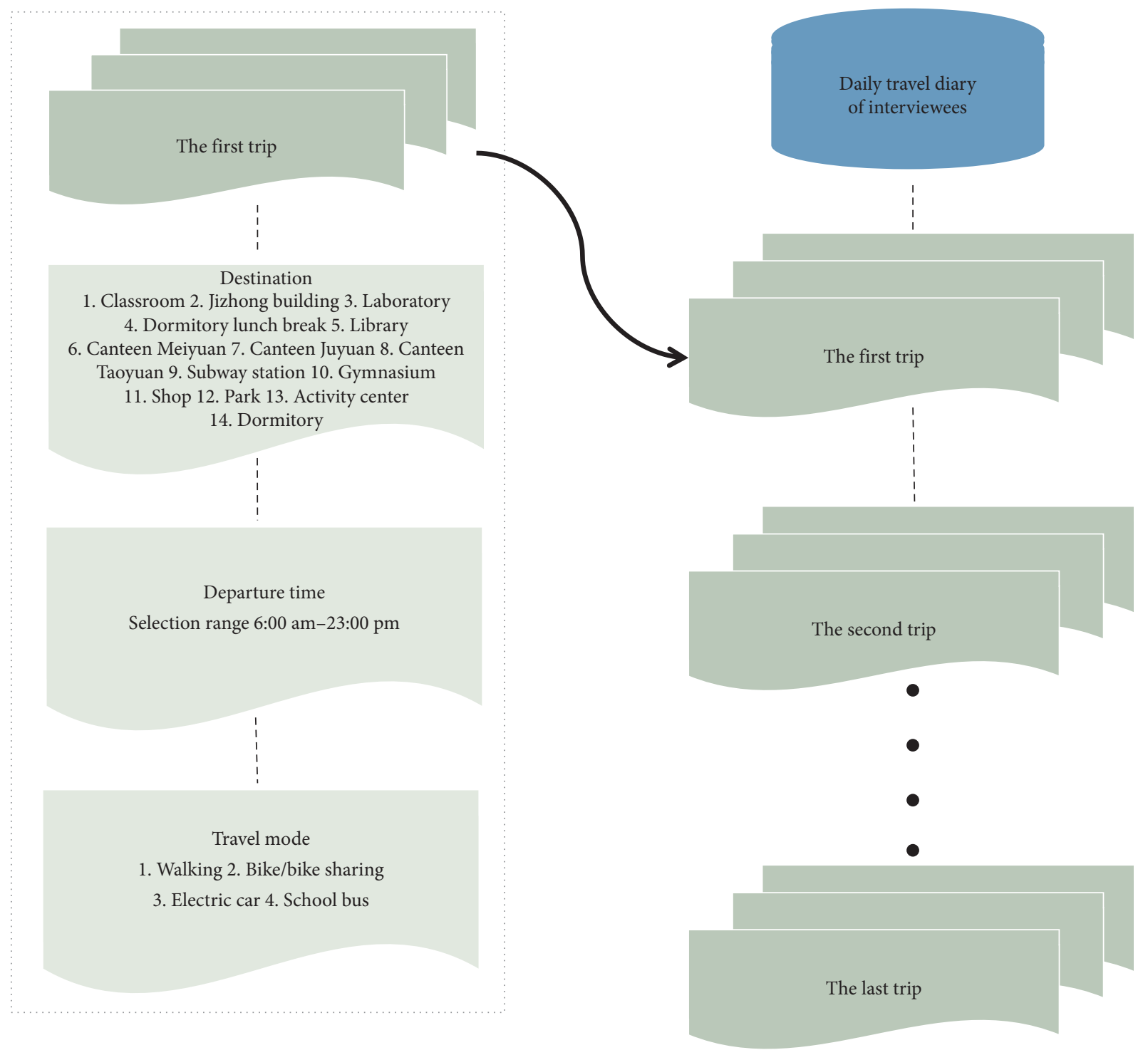

Figure 4: Structure of travel diary survey in RP scenario.

which leads to B3. As shown in B4, the most intensive time for students to go back to the library is B4. Therefore, according to the time distribution characteristics of weekend and nonweekend activities, corresponding arrangements can be made for the opening hours of libraries, gymnasiums, activity centers, and other places. For example, the weekend library, taking into account the uniform distribution of activities in the time dimension, can implement the layered time period closing mode.

In addition to visualizing the space-time path under the existing space environment, this paper also analyzes the space-time path under different assumptions, as shown in Figure 7 . They are the space-time path map of weekend and nonweekend under different assumption space environments.

Different colors in the figure represent different locations of bus platforms. On weekends (the upper line in Figure 7), it can be found that bus stops are set up near the north gate and the library. There is no significant difference between the trip distribution and that in Figure 8 . There is still a dense distribution in the morning and noon, and then a uniform distribution after dinner. However, when the bus stops are located near the gymnasium, the activity trip after dinner changes from uniform distribution to two more intensive distribution, as indicated by the black arrow in the figure. This may be because on weekends, when bus stops are set up near the gymnasium, some travelers will be more willing to go to the gymnasium for a period of time after dinner and then return to the dormitory. This phenomenon is reasonable. After increasing the number of bus stops, students can go directly to the dormitory after exercise. They do not need to walk or ride back to the dormitory, and they do not need to consider the fatigue of going back to the dormitory after exercise. Therefore, students' willingness to go to the gym in their spare time after eating on weekends is also increased. Therefore, in the weekend, the operation of bus stops near the stadium can be selected after 4.00 


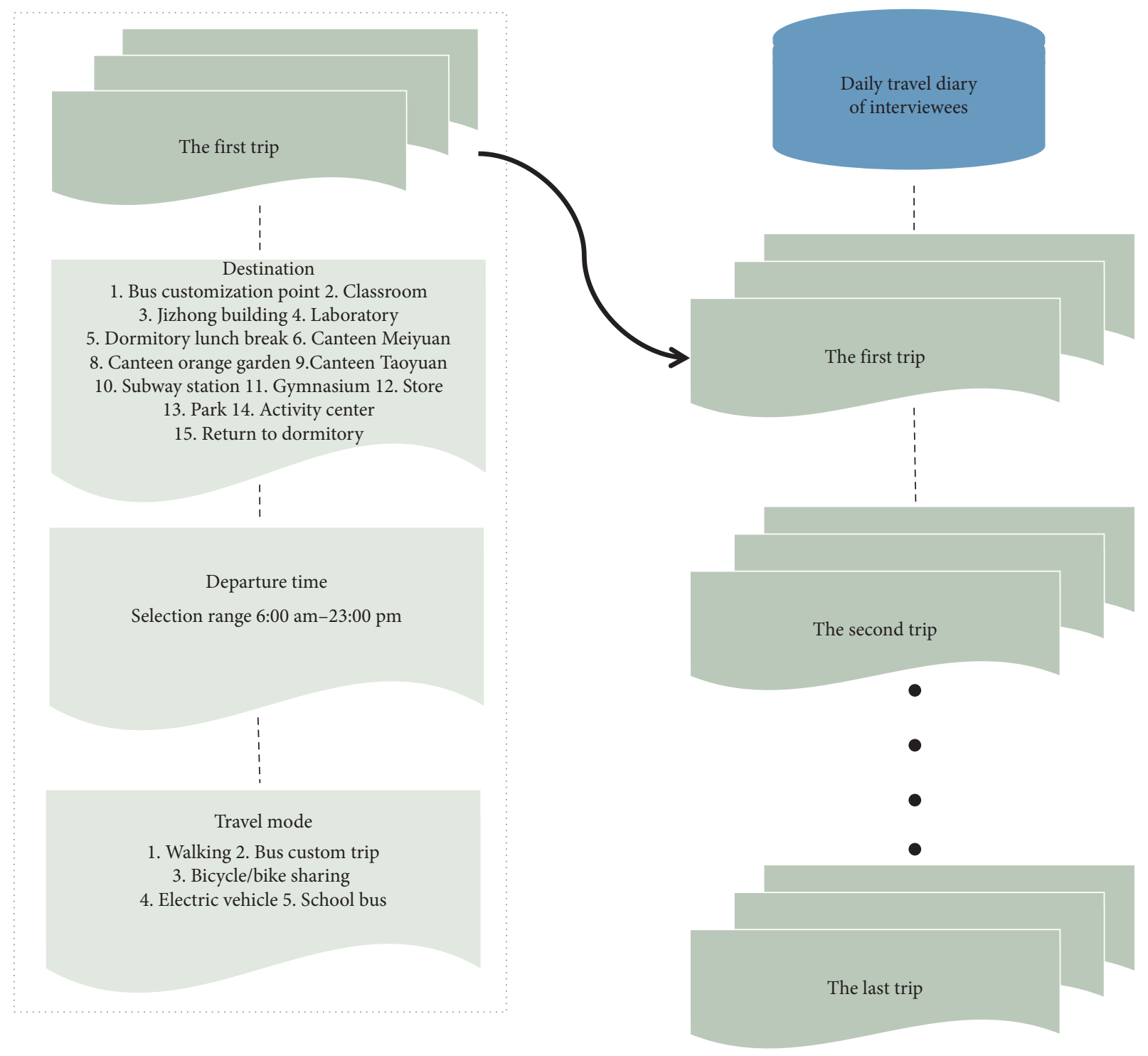

Figure 5: Structure of travel diary survey in the SP scenario.

pm. At this time, on the one hand, students' interest in sports can be improved, and on the other hand, the operation cost can be saved.

For weekdays, as shown in the lower line of Figure 7, no matter where the bus stops are set, the temporal distribution of the spatiotemporal routes is consistent with the existing spatial environment of weekdays (the right column of Figure 8), basically including four dense routes. Because on weekdays, students' main activity needs are learning, and their activity habits will not change, so the distribution of space-time path in time dimension has no obvious change. Therefore, consistent with the conclusion of the ANOVA test in the previous section, it is suggested to reduce the operation time and operation cost of the unmanned bus platform on weekdays.

5.2. Dynamic Activity Density Analysis. The above discussion is about the temporal distribution of travelers' spatiotemporal paths. However, at different times of the day, the location of the traveler's activities is also changing. In order to understand the spatial distribution of travelers in different times, a dynamic activity density distribution tool was developed. This tool can get the space activity point position of each traveler at a given time. Therefore, the distribution of active points at different times can be compared.

Figure 9(a) shows a total of 190 trip paths in the weekend RP and SP survey, and Figure 9(b) shows a total of 154 trip paths in the weekday RP and SP survey. Then, the distribution of space activity points every three hours from 9:00 am to $21: 00 \mathrm{pm}$ is obtained. The Yellow plane represents different times, and the red point represents the location of different travelers on a certain time section. Figures 10(a), $9(\mathrm{a})$, and $10(\mathrm{~b})$, respectively, show the spatial distribution of the nuclear density of the active points at different times, which is in line with the expectation. It can be clearly seen that on weekends, the distribution of activity spots is 
TABLE 2: Descriptive statistics of social attributes.

\begin{tabular}{|c|c|c|c|}
\hline Variable name & Description & Number & Percentage \\
\hline \multirow{2}{*}{ Are you an undergraduate } & No & 25 & 14.53 \\
\hline & Yes & 147 & 85.47 \\
\hline \multirow{2}{*}{ Subject type } & Liberal arts & 37 & 21.51 \\
\hline & Science and engineering & 135 & 78.49 \\
\hline \multirow{2}{*}{ Gender } & Female & 85 & 49.42 \\
\hline & Male & 87 & 50.58 \\
\hline \multirow{2}{*}{ Family } & Rural & 48 & 27.91 \\
\hline & Town & 124 & 72.09 \\
\hline \multirow{3}{*}{ Dormitory } & Tao Yuan & 109 & 63.37 \\
\hline & Mei Yuan & 54 & 31.40 \\
\hline & Ju Yuan & 9 & 5.23 \\
\hline \multirow{5}{*}{ Schoolwork burden } & Very heavy & 22 & 12.79 \\
\hline & Heavy & 81 & 47.09 \\
\hline & Commonly & 59 & 34.30 \\
\hline & Relaxed & 7 & 4.07 \\
\hline & Very relaxed & 3 & 1.74 \\
\hline \multirow{4}{*}{ GPA ranking } & $20 \%$ & 53 & 30.81 \\
\hline & $20 \%-50 \%$ & 52 & 30.23 \\
\hline & $50 \%-80 \%$ & 55 & 31.98 \\
\hline & $80 \%$ & 12 & 6.98 \\
\hline \multirow{4}{*}{ Living expenses (yuan) } & $<1000$ & 21 & 12.21 \\
\hline & $1000 \sim 1500$ & 62 & 36.05 \\
\hline & $1500 \sim 2000$ & 59 & 34.30 \\
\hline & $2000 \sim$ & 30 & 17.44 \\
\hline \multirow{2}{*}{ Only child or not } & No & 77 & 44.77 \\
\hline & Yes & 95 & 55.23 \\
\hline \multirow{2}{*}{ Do you have a boyfriend/girlfriend } & No & 70 & 40.70 \\
\hline & Yes & 102 & 59.30 \\
\hline
\end{tabular}

TABLE 3: ANOVA test of total travel distance.

\begin{tabular}{|c|c|c|c|c|c|}
\hline & & \multicolumn{2}{|c|}{ Weekend } & \multicolumn{2}{|c|}{ Working day } \\
\hline & & Mean difference $(I-J)$ & Standard error & Mean difference $(I-J)$ & Standard error \\
\hline \multirow{3}{*}{1} & 2 & $-998.41^{* *}$ & 411.79 & 165.68 & 416.19 \\
\hline & 3 & $-1287.60^{* * *}$ & 390.42 & $-962.59^{*}$ & 409.10 \\
\hline & 4 & $-1081.05^{* *}$ & 445.92 & -287.31 & 362.10 \\
\hline \multirow{3}{*}{2} & 1 & $998.41^{* *}$ & 411.79 & 165.68 & 416.19 \\
\hline & 3 & -289.19 & 486.36 & -796.91 & 513.41 \\
\hline & 4 & -82.64 & 531.94 & -121.63 & 476.81 \\
\hline \multirow{3}{*}{3} & 1 & $1287.60^{* * *}$ & 390.42 & $-962.59^{*}$ & 409.10 \\
\hline & 2 & 289.19 & 486.36 & 796.91 & 513.41 \\
\hline & 4 & 206.55 & 515.57 & 675.28 & 470.63 \\
\hline \multirow{3}{*}{4} & 1 & $1081.05^{* *}$ & 445.92 & 287.31 & 362.10 \\
\hline & 2 & 82.64 & 531.94 & 121.63 & 476.81 \\
\hline & 3 & 206.55 & 515.58 & -675.28 & 476.63 \\
\hline
\end{tabular}

1: no shared bus point; 2 : near north gate; 3 : in front of library; 4 : beside gymnasium. ${ }^{* * *}$ : significant at 0.001 level, ${ }^{* *}:$ significant at 0.01 level, and ${ }^{*}$ : significant at 0.05 level.

relatively uniform, mainly concentrated in the library, dormitory, and classroom areas. On the other hand, on weekdays, classrooms are the main places for students to concentrate. After 18:00 pm, this situation becomes different and begins to be evenly distributed in other main places on the campus. At the same time, it can be noted that the distribution density of the weekend in the subway station is significantly higher than that in the working day. From about 12 noon, the density of the activity points in the subway station on the weekend began to increase significantly. This phenomenon lasted at least until after 18.00 p.m., and only after 15.00 p.m. on the working day. There is a slight activity density distribution in the subway station at any time, and it is flat at other times.

The distribution pattern of activity density on weekends and weekdays brings some inspiration to the design of campus 
TABle 4: ANOVA test of total activity duration.

\begin{tabular}{|c|c|c|c|c|c|}
\hline & \multicolumn{2}{|c|}{ Weekend } & \multicolumn{2}{|c|}{ Working day } \\
\hline & & Mean difference $(I-J)$ & Standard error & Mean difference $(I-J)$ & Standard error \\
\hline \multirow{3}{*}{1} & 2 & 12.632 & 42.34 & -14.29 & 49.00 \\
\hline & 3 & -39.125 & 40.15 & -44.19 & 48.17 \\
\hline & 4 & -17.753 & 45.85 & -24.91 & 42.63 \\
\hline \multirow{3}{*}{2} & 1 & -12.632 & 42.34 & 14.29 & 49.00 \\
\hline & 3 & -51.757 & 50.01 & 58.48 & 60.45 \\
\hline & 4 & -30.385 & 54.70 & -10.63 & 56.14 \\
\hline \multirow{3}{*}{3} & 1 & 39.125 & 40.15 & -44.19 & 48.17 \\
\hline & 2 & 51.757 & 50.01 & -58.48 & 60.45 \\
\hline & 4 & 21.372 & 53.02 & -69.10 & 55.41 \\
\hline \multirow{3}{*}{4} & 1 & 17.753 & 45.85 & 24.91 & 42.63 \\
\hline & 2 & 30.385 & 54.70 & 10.63 & 56.14 \\
\hline & 3 & -21.372 & 53.02 & -69.10 & 55.41 \\
\hline
\end{tabular}

1: no shared bus point; 2: near north gate; 3 : in front of library; 4: beside gymnasium.

TABLE 5: Analysis of influencing factors based on activity travel behavior analysis (weekdays).

\begin{tabular}{|c|c|c|c|c|c|c|c|}
\hline & & \multicolumn{3}{|c|}{$\begin{array}{l}\text { Scale heterogeneity is not } \\
\text { considered }\end{array}$} & \multicolumn{3}{|c|}{$\begin{array}{l}\text { Considering scale } \\
\text { heterogeneity }\end{array}$} \\
\hline & & Coef. & Sig. & S.E. & Coef. & Sig. & S.E. \\
\hline Other leisure choices interc & & -19.08 & $* * *$ & 3.92 & -15.10 & $* * *$ & 3.67 \\
\hline \multicolumn{8}{|l|}{ Personal attribute variable } \\
\hline \multirow[t]{4}{*}{ ter } & $\sim 20 \%$ & - & - & - & - & - & - \\
\hline & $20 \% \sim 50 \%$ & -1.17 & - & 0.94 & -0.93 & - & 0.72 \\
\hline & $50 \% \sim 80 \%$ & -17.17 & - & 921.15 & -74 & - & 975.29 \\
\hline & $80 \% \sim 100 \%$ & 0.25 & - & 1.04 & 0.16 & - & 0.88 \\
\hline \multirow{4}{*}{ Living expenses (yuan) } & $\sim 1000$ & - & - & - & - & - & - \\
\hline & $1000 \sim 1500$ & -16.08 & - & 975.29 & -94.6 & - & 0.73 \\
\hline & $1500 \sim 2000$ & -13.43 & - & 975.29 & -92.6 & - & 0.52 \\
\hline & $2000 \sim$ & -12.82 & - & 975.29 & -92.1 & - & 0.55 \\
\hline \multirow{2}{*}{ Is he or she the only child } & No & - & - & - & - & - & - \\
\hline & Yes & 15.58 & - & 975.29 & 12.3 & - & 975.29 \\
\hline \multicolumn{8}{|l|}{ Travel-related variables } \\
\hline Remaining time budget & & -11.63 & $* * *$ & 2.77 & -9.47 & $* * *$ & 2.50 \\
\hline Time and distance (min) & & 0.49 & $* * *$ & 0.14 & 0.38 & $* * *$ & 0.97 \\
\hline \multirow{4}{*}{ Travel mode } & Walk & - & - & - & - & - & - \\
\hline & Bicycle & 7.45 & $* * *$ & 1.78 & 5.55 & $* * *$ & 1.64 \\
\hline & Electric vehicle/school bus & -8.74 & - & 3090.52 & -12.5 & - & 8200 \\
\hline & Sharing customized bus & 9.45 & $* * *$ & 2.07 & 7.22 & $* * *$ & 1.91 \\
\hline
\end{tabular}

${ }^{* * *}$ : significant at 0.001 level, ${ }^{* *}$ : significant at 0.01 level, and ${ }^{*}$ : significant at 0.05 level.

space, such as the scheduling and placement of shared bicycles in and around the campus. In the case of a certain number of bike sharing, rational use of the spatial distribution of activities can maximize the utility. For example, on weekdays, the supply of shared bicycles near dormitories and teaching buildings should be increased, and on weekends, the supply of shared bicycles between subway stations and dormitories should be prioritized. In addition, there should also be a special dynamic parking area for bike sharing to adapt to the dynamic distribution of activity points, so as to manage bike sharing orderly and make full use of land resources at the same time. In addition, during the working days, students are mainly concentrated near the teaching building, especially between the dormitory and the teaching building. During the morning, middle, and evening peak hours, the crowd is very dense. Therefore, a separation channel between people and vehicles in the students' round-trip journey should be set up, a car-free area to separate bicycles and pedestrians should be created, and motor vehicles should be instructed to detour, which also ensures the order of bicycle travel. In addition, under this design, the unmanned shared bus can be operated more conveniently, efficiently, and safely.

5.3. Spatiotemporal Path Clustering Analysis. In this paper, Chen's method [26] is used for reference, as shown in Figure 11, and $3 \mathrm{D}$ is transformed into $2 \mathrm{D}$ to cluster spatiotemporal paths. The specific methods are as follows: 
TABLE 6: Cox regression results.

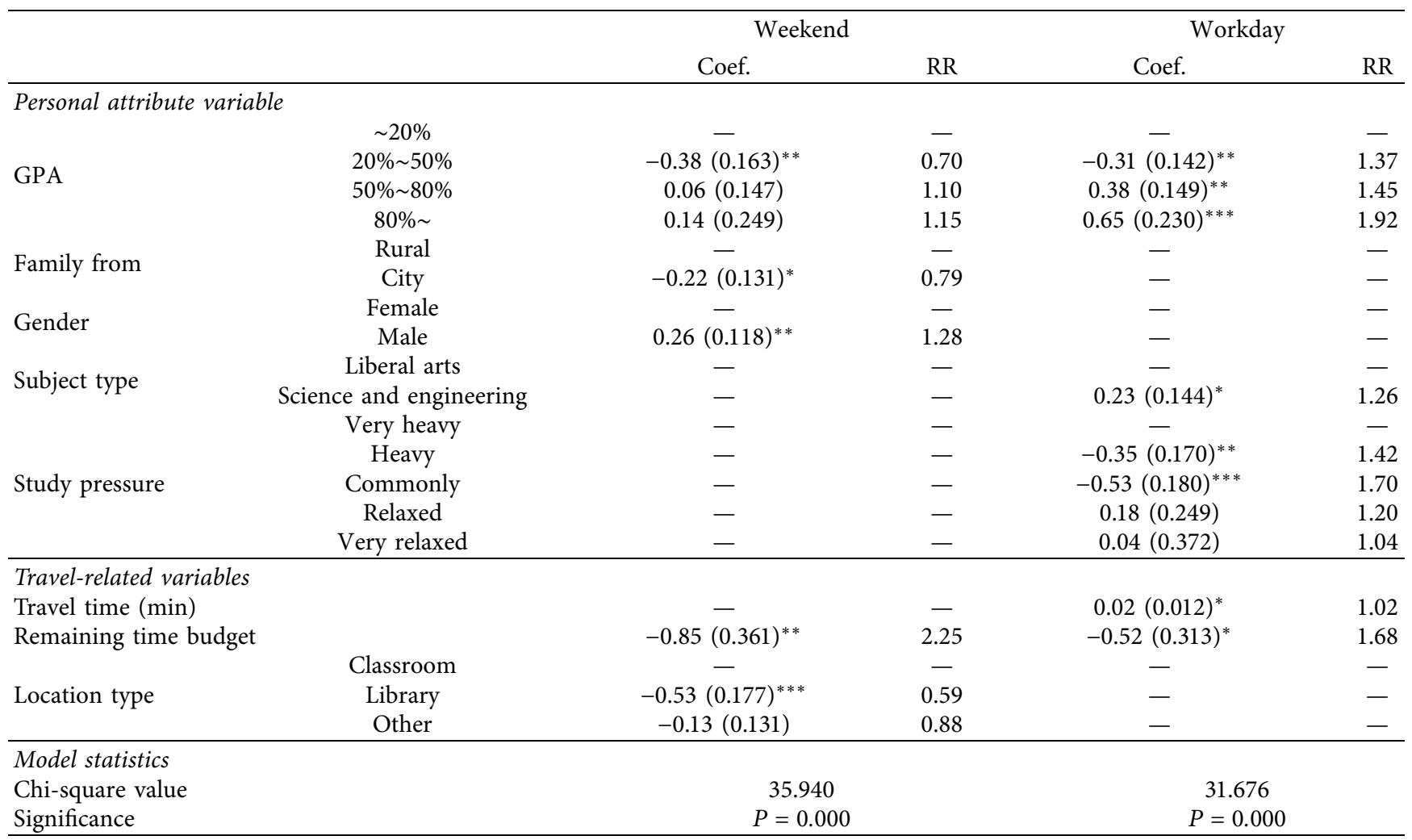

Significance: ${ }^{*} p<0.05,{ }^{* *} p<0.01$, and ${ }^{* * *} p<0.001$.

(1) Firstly, the three-dimensional space-time path is transformed into the two-dimensional time distance coordinate system, and the absolute distance from the dormitory at any time in the space-time path in Figure 11(a) is transformed into the ordinate in the twodimensional coordinate system, and the time dimension is abscissa. Although the information such as the direction of movement is put aside, a lot of effective information, such as activity time, sequence, frequency, and so on, is still retained. This method can express the space-time route clearly, which is helpful to analyze the travel trajectory of people.

(2) After obtaining the transformation coordinate system in Figure 11(b), the similarity of the two spatiotemporal paths based on the overlap area of the two paths will be calculated. The similarity calculation formula is as follows:

$$
D=\frac{c}{a+b-c}
$$

where $D$ is the ratio of the overlapping area of $a$ and $B$ paths to the total area. $C$ is the overlapping area between $a$ and $B, a$ is the area between the coordinate transformation of path a and the time axis, and $B$ is the area between the coordinate transformation of path $B$ and the time axis. Therefore, the larger the $D$ value is, the higher the coincidence degree is, and the more similar it is.
(3) Based on the above method, the similarity $d$ between two spatiotemporal paths can be calculated, and then the similarity matrix of all spatiotemporal paths can be obtained, as shown in Figure 12. Red, blue, and yellow represent paths 1, 2, and n, respectively. D12, $\mathrm{D} 1 n$, and D2 $n$, respectively, represent the similarity between paths 1 and 2 , paths 1 and $n$, and paths 2 and $n$.

(4) After getting the similarity matrix, hierarchical clustering method is used to cluster the spatiotemporal travel paths with similarity $D$ as the distance index. In the hierarchical clustering algorithm, the average distance is selected as the distance parameter between clusters.

According to the above methods, a spatiotemporal path clustering tool is built in ArcGIS to calculate the path similarity matrix under weekend and weekday conditions. For the sake of clustering effect, SP survey diary and RP survey diary are merged here. Finally, according to the clustering results, the appropriate number of categories is selected. The weekend clustering results are shown in Figure 13.

After removing some edge categories, the weekend travel space-time path is divided into three categories. The paths within categories are similar, but there are obvious differences between categories. The first category (classroom + library) represents the learning category. The location of travel activities involves teaching buildings and 


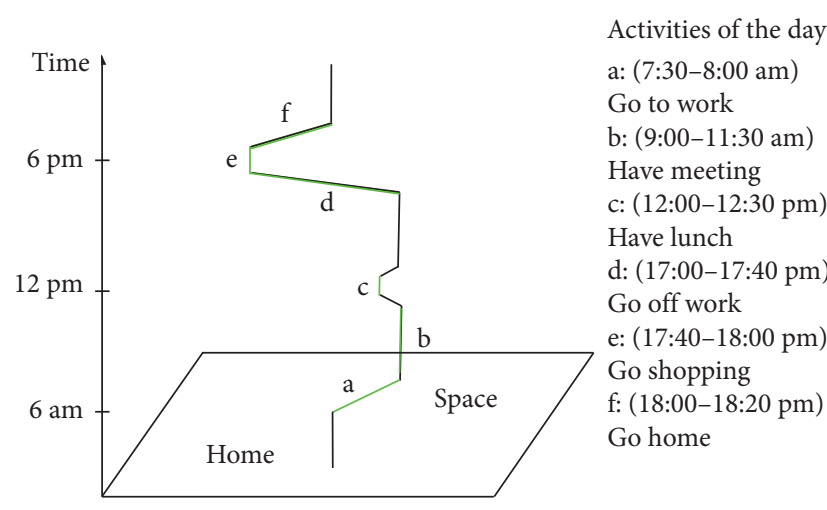

(a)

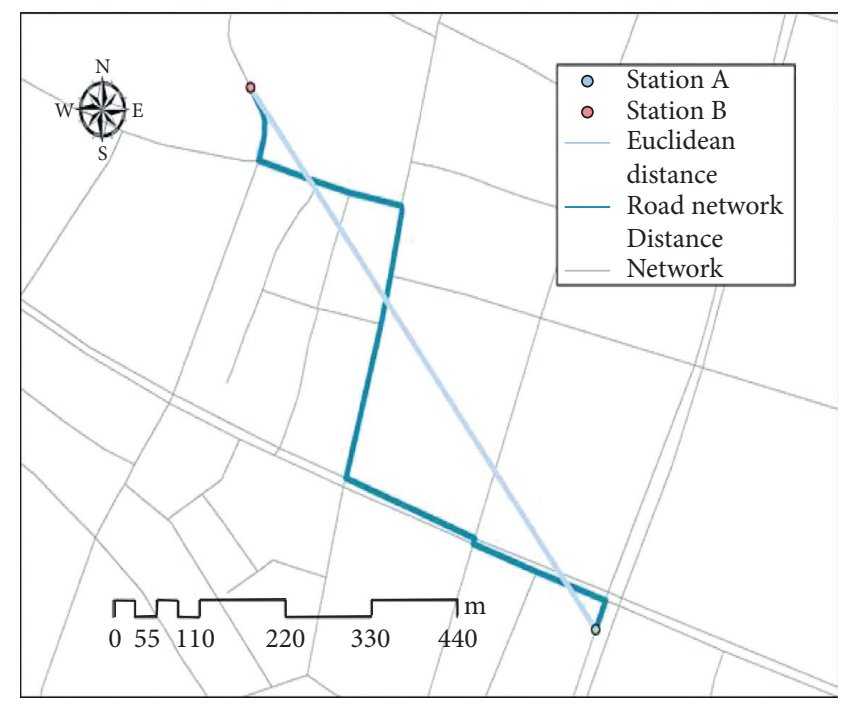

(b)

FIgURE 6: Space time path map. (a) Time space path diagram. (b) Spatial path map.
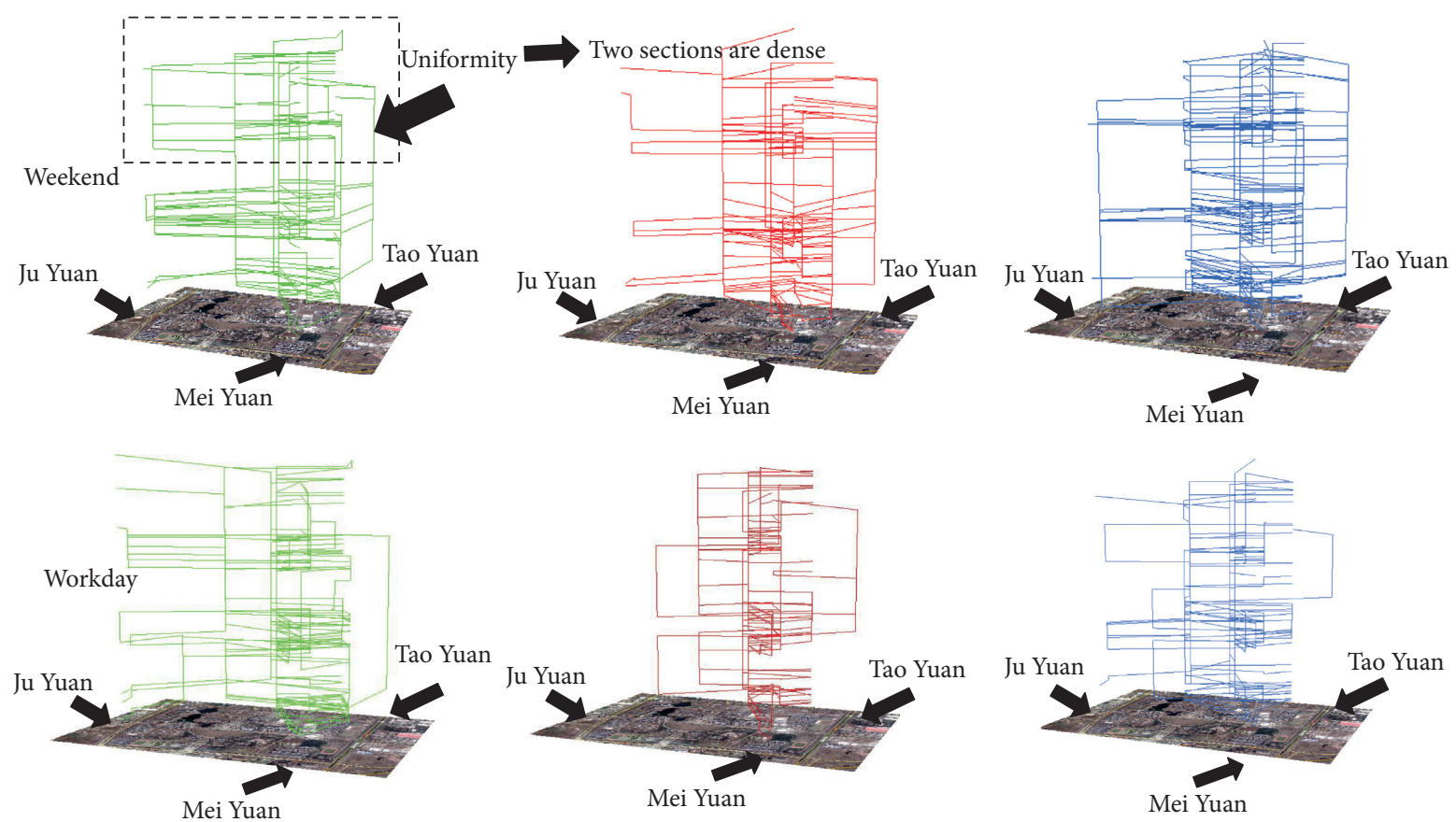

— Gymnasium

— Beimen

- Library

Figure 7: Activity travel path map of bus customization platform in different locations.

classrooms. It can be seen that even on weekends, less than half of the students will go to the teaching building for selfstudy. The second category (canteen) represents the rest type. It can be seen from Figure 13 that most people travel between the dormitory and canteen, and there are no other activities. This kind of living habit is not good for health. Therefore, some attractive facilities can be set up near the canteen, such as cat cafes and fitness equipment, to change the habit and reduce the time in the dormitory. In contrast, the third category (diversity category), namely, activity rich type, has a longer travel distance, involving eating in the orange garden or going out to subway station for other activities. In the three categories, diverse categories account for the largest proportion, which is also in line with the expectation. Because the learning tasks are easier on weekends, students will have more time to control, and the 


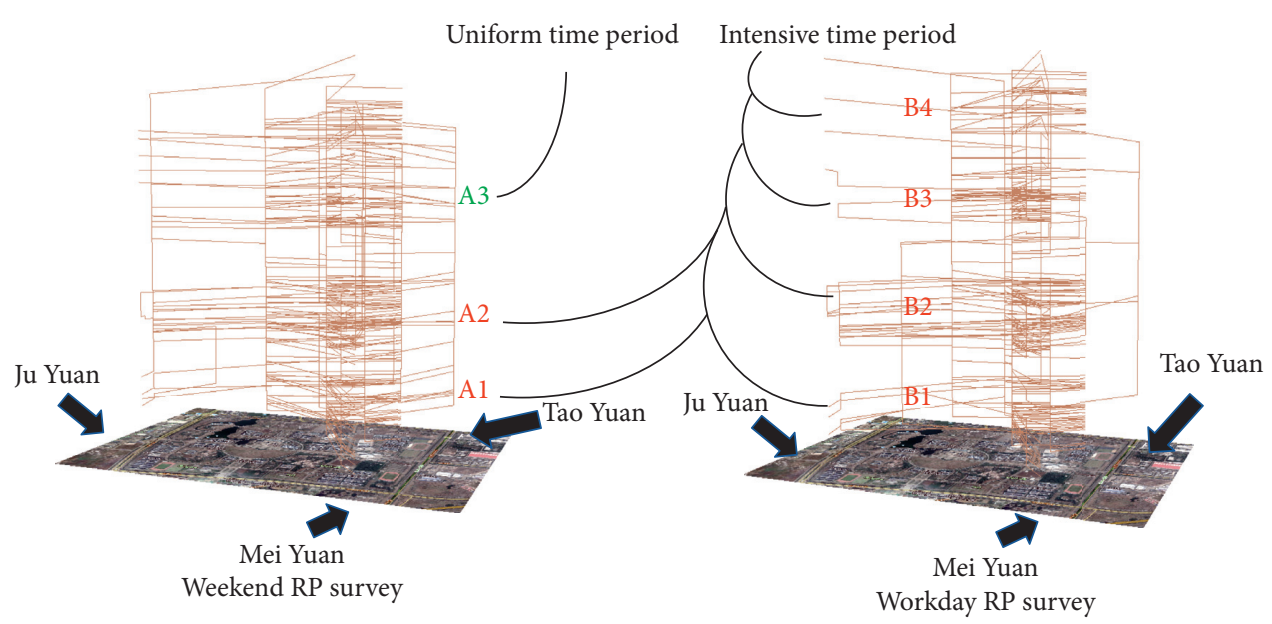

Figure 8: Activity travel path under RP survey.

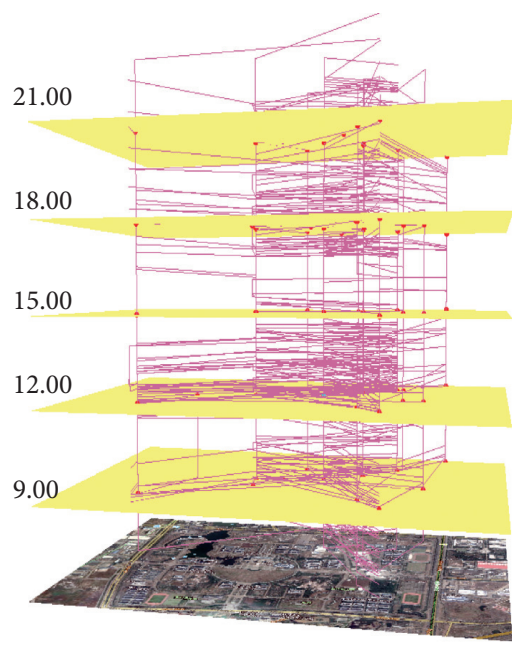

(a)

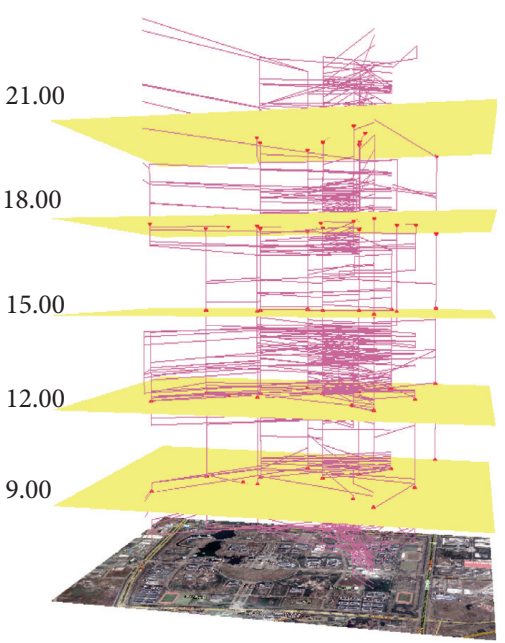

(b)

Figure 9: Distribution of activity points at different times on (a) weekends and (b) weekdays.

acceptable travel distance will also increase, so they will go to the subway station on weekends and then go to other places to relax. In view of this situation, the number of school buses in the peak period of weekend lunch and dinner can be increased, and the operation of bus customized travel points should be shared. This can not only meet the needs of the dormitory and the orange garden canteen but also meet the needs of the connection between the school and the subway station.

Compared with weekends, Figure 14 shows the travel classification chart of weekdays, which can be divided into four categories. Among the four categories, the first and the second account for the largest proportion. Compared with other categories, the first category (early return category) has an earlier schedule to finish the day, and basically returns to the dormitory after dinner, which belongs to the early return category. The second category (classroom + library) and the third category (classroom) belong to the same learning type, but the difference is that the second category includes classrooms and libraries, the third category only includes classrooms, and the second category has more travelers than the third category, which indicates that most students will go to both libraries and classrooms in one day. The fourth type (diversity type) and the second type (classroom + library) are similar, both of which involve the library and classroom. However, the difference is that the fourth type will choose to eat in the orange garden at noon, and the travel distance is larger than the classroom + library type, and the number of people is also smaller. As expected, the working day travel places are concentrated in the classroom and the library, so setting a place for students to rest after study somewhere between the classroom and the library can be considered, which can not only help students relax but also create a certain consumer demand. In addition, due to the huge flow 


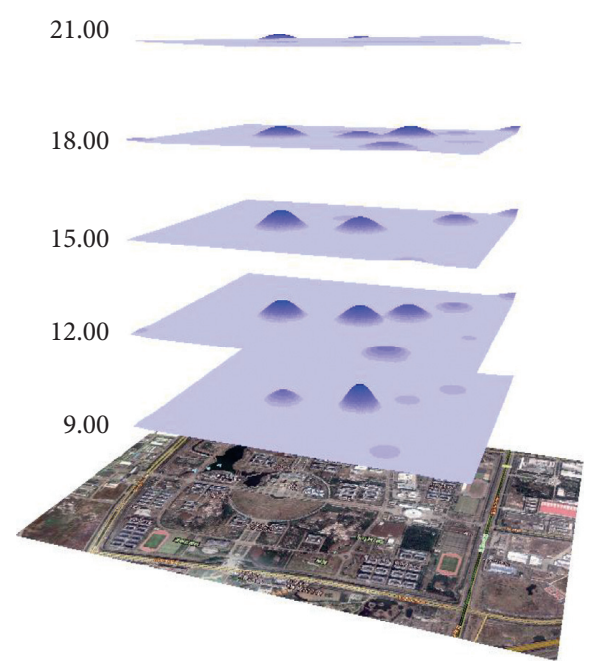

(a)

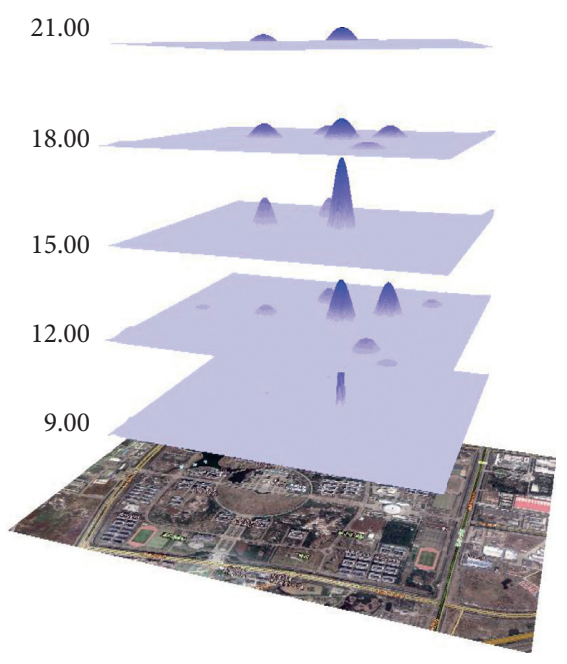

(b)

Figure 10: Density distribution of dynamic activity points on (a) weekends and (b) weekdays.

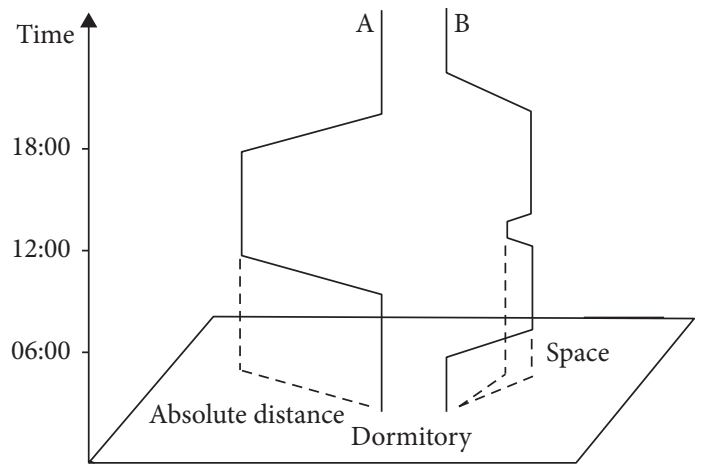

(a)

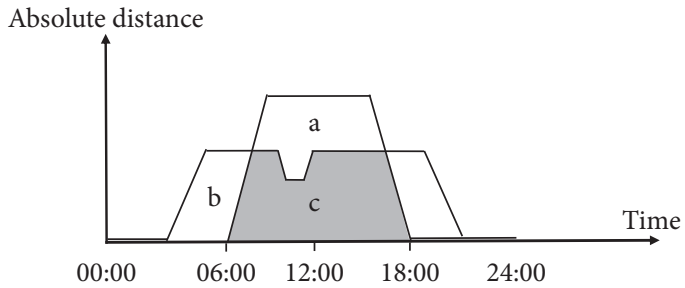

(b)

FIgURE 11: Similarity measurement method based on spatiotemporal path. (a) Three-dimensional spatiotemporal path. (b) Two-dimensional time-distance coordinate system diagram.

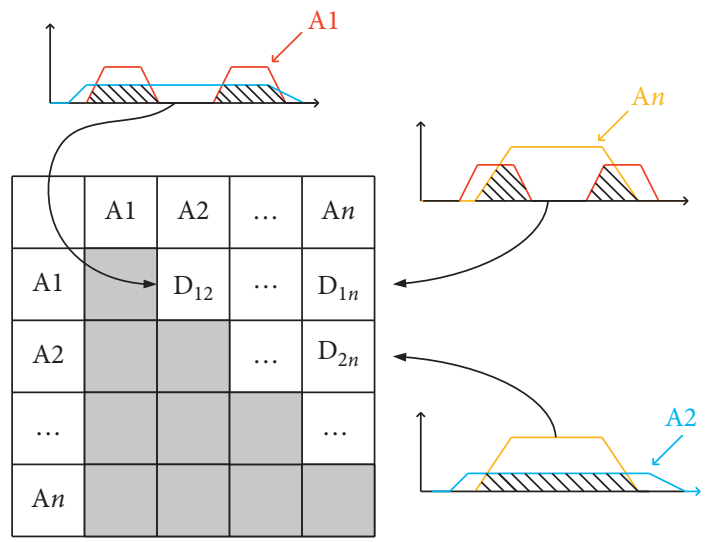

FIGURE 12: Similarity matrix of spatiotemporal path. 


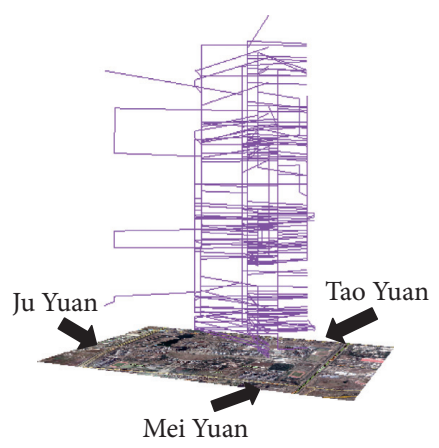

(a)

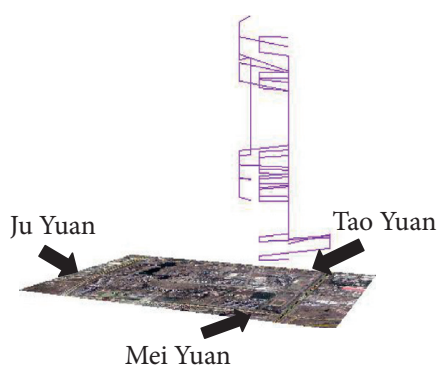

(b)

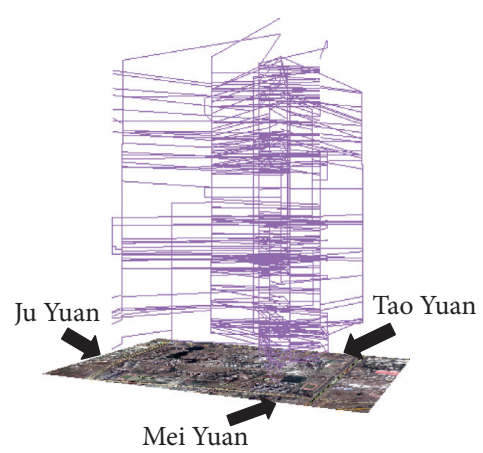

(c)

FIgURE 13: Weekend activities travel pattern classification. (a) Classroom + library, (b) canteen, and (c) diversity.

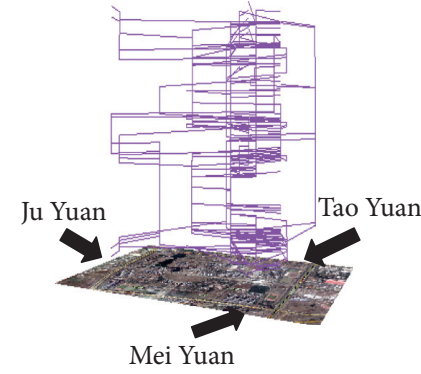

(a)

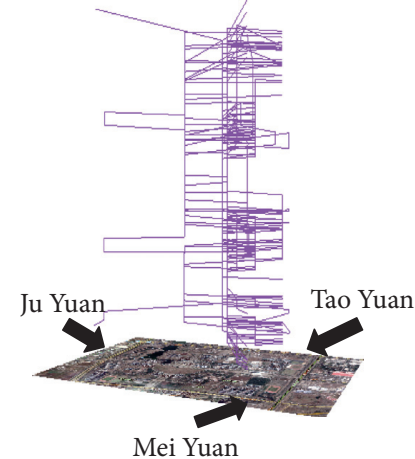

(b)

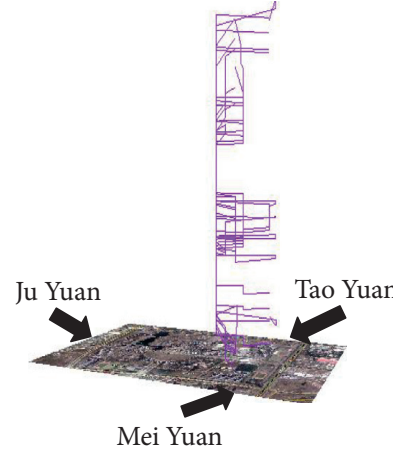

(c)

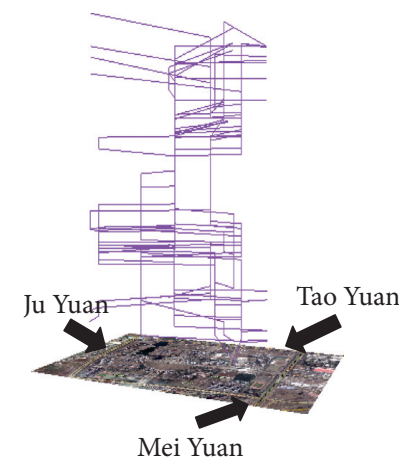

(d)

FIgURE 14: Weekday activity travel pattern classification. (a) Early return, (b) classroom + library, (c) classroom, and (d) diversity.

between the library and the classroom, the sun shading corridor can be set between the library and the classroom to ensure that even on rainy days or hot weather, it is convenient to go back and forth between the two places.

\section{Conclusion}

In the framework of activity-based travel concept, this study analyzes the activity travel behavior of travelers from the overall perspective of travel diary, explores the impact of campus shared bus on students' travel, and optimizes the space environment according to the analysis results.

With regard to data collection, in order to eliminate the interference of too many random factors, the survey object is determined as full-time college students with regular travel behavior, and the survey location is determined as the Jiulonghu campus of Southeast University, which has a large campus area and can reflect the travel differences. In the process of questionnaire design, the combination of SP survey and RP survey is considered to improve the richness of questionnaire information. In the SP scenario, this paper proposes the idea of sharing the customized travel platform of unmanned bus, and places these platforms near the north gate, library, and gymnasium in the campus. Under these three SP scenarios and the existing RP scenario, the personal attributes and travel diary of travelers are investigated. In addition, travel differences between weekends and weekdays are also taken into account.

With regard to the analysis of traveler's activity travel behavior, the temporal and spatial characteristics of activity travel behavior are firstly mined. This paper introduces the concept of spatiotemporal geography; develops the tools in ArcGIS platform; constructs the activity travel path generation tool, dynamic activity density distribution tool, and activity travel path clustering tool; establishes a multidimensional activity travel behavior analysis system; and conducts comprehensive and efficient spatiotemporal feature mining. Then, according to the psychological process of activity decision-making and the particularity of college students, the location selection model (S$\mathrm{MNL}$ ) considering the heterogeneity of SP and RP data sources and the activity duration planning model (Cox regression) considering the nonnormal distribution of activity duration are established, respectively, reflecting the internal relationship of different activities in travel diary.

At the same time, according to the results of activity travel behavior analysis, the campus space environment is optimized. According to the temporal and spatial characteristics of travel diary, there are differences in time distribution and geographical distribution between weekend and weekday activity travel patterns. In terms of geographical distribution, the activity locations on weekends are more uniform than those on weekdays, so 
the scheduling of shared bicycles on campus needs to be combined with their differences. In addition, considering that the activities on weekdays are too concentrated in the classroom, a car-free area can be created to separate bicycles and pedestrians, so as to streamline the traffic around the classroom. The spatiotemporal path clustering tool divides weekend travel and weekday travel into three categories and four categories, respectively, and gives analysis and campus optimization suggestions based on the characteristics of different categories. For example, for people who only go to and from dormitory and canteen on weekends, fitness equipment or cat cafes can be set near canteen to enrich their activity types; because a large number of students will go to and from library on weekdays and between classrooms, it is suggested to set up a sun shading-corridor connecting the classroom and the library. The results of the S-MNL model show that the fitting degree of weekend and nonweekend models are improved after considering the scale heterogeneity. Whether on weekends or weekdays, using electric vehicles to travel will increase the willingness to go to the library (with the classroom as a reference). For this, electric vehicle charging piles can be set near the library. In addition, compared with setting near the north gate, setting the customized bus platform near the gymnasium can promote the diversity of activities. According to Cox regression results, compared with working days, travelers are not sensitive to travel time on weekends. Therefore, the concept of walking campus on weekends can be promoted, the appearance of sidewalks can be improved, and special jogging or pedestrian roads connecting all parts of the campus can be established.

The innovation of this paper mainly lies in two aspects: first, for travel behavior analysis, most of the previous studies are based on single trip research. Trip-based studies focus on a segment of the daily trip chain, for example, the travel mode choice and satisfaction on the single trip from home to the subway station. Lack of overall understanding of a day's travel activities will lead to a one-sided analysis. In order to make up for the deficiency of single-trip-based research, this paper focuses on more trip information, including different activity locations, activity duration, activity trip times, etc., in the framework of activity-based trip concept, and conducts spatiotemporal feature mining and modeling analysis on the whole trip diary. Second, the spatial environment is the focus of this paper, but most of the studies are based on the impact of the existing built environment on the traffic trip, the data lack flexibility, researchers cannot know the response of the same traveler in different built environments, and the comparability decreases. Therefore, this paper uses the survey method based on declarative preference SP and the survey method based on explicit preference (RP) to get the actual and hypothetical travel response of travelers, which improves the data richness.

\section{Data Availability}

The data used to support the findings of this study have not been made available, because some data used during the study are proprietary or confidential in nature.

\section{Conflicts of Interest}

The authors declare that they have no conflicts of interest.

\section{Acknowledgments}

This work was supported by the National Key Research and Development Program of China (no. 2019YFB1600200), the National Natural Science Foundation of China (nos. 71971056 and 51608115), Research the Technologies of Passenger Stations in Beijing-Tianjin-Hebei Region (no. P2018G049), the Six Talent Peaks Project in Jiangsu Province (no. XNYQC-003), and the Science and Technology Project of Jiangsu Province, China (no. BZ2020016).

\section{References}

[1] Y. Shiftan, "The use of activity-based modeling to analyze the effect of land-use policies on travel behavior," The Annals of Regional Science, vol. 42, no. 1, pp. 79-97, 2008.

[2] R. Cervero and K. Kockelman, "Travel demand and the 3Ds: density, diversity, and design," Transportation Research Part D: Transport and Environment, vol. 2, no. 3, pp. 199-219, 1997.

[3] Y. Liu, D. Yang, H. J. P. Timmermans, and B. de Vries, "Analysis of the impact of street-scale built environment design near metro stations on pedestrian and cyclist road segment choice: a stated choice experiment," Journal of Transport Geography, vol. 82, p. 102570, 2020.

[4] R. Crane, "On form versus function: will the new urbanism reduce traffic, or increase it?" Journal of Planning Education and Research, vol. 15, no. 2, pp. 117-126, 1996.

[5] M. Malayath and A. Verma, "Activity based travel demand models as a tool for evaluating sustainable transportation policies," Research in Transportation Economics, vol. 38, no. 1, pp. 45-66, 2013.

[6] A. Rosa, T. Oliveira, H. Nunes et al., "Guidelines to design bicycle routes on university campuses: a case study at the federal university of Viçosa," Case Studies on Transport Policy, vol. 8, no. 2, pp. 620-626, 2020.

[7] K. D. Vo, W. H. K. Lam, A. Chen et al., "A household optimum utility approach for modeling joint activity-travel choices in congested road networks," Transportation Research Part B: Methodological, vol. 134, pp. 93-125, 2020.

[8] Q. Li, F. Liao, H. J. P. Timmermans et al., "Incorporating freefloating car-sharing into an activity-based dynamic user equilibrium model: a demand-side model," Transportation Research Part B: Methodological, vol. 107, pp. 102-123, 2018.

[9] A. Bassolas, J. J. Ramasco, R. Herranz et al., "Mobile phone records to feed activity-based travel demand models: MATSim for studying a cordon toll policy in Barcelona," Transportation Research Part A: Policy and Practice, vol. 121, pp. 56-74, 2019.

[10] B. H. Nahmias-Biran and Y. Shiftan, "Towards a more equitable distribution of resources: using activity-based models and subjective well-being measures in transport project evaluation," Transportation Research Part A: Policy and Practice, vol. 94, pp. 672-684, 2016.

[11] S. F. A. Baqueri, M. Adnan, B. Kochan, and F. Bellemans, "Activity-based model for medium-sized cities considering external activity-travel: enhancing FEATHERS framework," Future Generation Computer Systems, vol. 96, pp. 51-63, 2019. 
[12] M. Zimmermann, O. Blom Västberg, E. Frejinger, and A. Karlström, "Capturing correlation with a mixed recursive logit model for activity-travel scheduling," Transportation Research Part C: Emerging Technologies, vol. 93, pp. 273-291, 2018.

[13] M. Fosgerau, E. Frejinger, and A. Karlstrom, "A link based network route choice model with unrestricted choice set," Transportation Research Part B: Methodological, vol. 56, pp. 70-80, 2013.

[14] H. C. Liu and J. J. Lin, "Associations of built environments with spatiotemporal patterns of public bicycle use," Journal of Transport Geography, vol. 74, no. 1, pp. 299-312, 2019.

[15] A. Chevalier, M. Charlemagne, and L. Xu, "Bicycle acceptance on campus: influence of the built environment and shared bikes," Transportation Research Part D: Transport and Environment, vol. 76, pp. 211-235, 2019.

[16] C. Ding and X. Cao, "How does the built environment at residential and work locations affect car ownership? an application of cross-classified multilevel model," Journal of Transport Geography, vol. 75, pp. 37-45, 2019.

[17] Y. Huang, X. Wang, and D. Patton, "Examining spatial relationships between crashes and the built environment: a geographically weighted regression approach," Journal of Transport Geography, vol. 69, pp. 221-233, 2018.

[18] L. Cheng, X. Chen, S. Yang et al., "Active travel for active ageing in China: the role of built environment," Journal of Transport Geography, vol. 76, pp. 142-152, 2019.

[19] B. Kutela and H. Teng, "The influence of campus characteristics, temporal factors, and weather events on campusesrelated daily bike-share trips," Journal of Transport Geography, vol. 78, pp. 160-169, 2019.

[20] A. Filipovitch and E. Frimpong Boamah, "A systems model for achieving optimum parking efficiency on campus: the case of Minnesota state university," Transport Policy, vol. 45, pp. 86-98, 2016.

[21] T. Limanond, T. Butsingkorn, and C. Chermkhunthod, "Travel behavior of university students who live on campus: a case study of a rural university in Asia," Transport Policy, vol. 18, no. 1, pp. 163-171, 2011.

[22] G. Alar, C. Flynn, and M. Namgung, "Travel choices and links to transportation demand management case study at Ohio state university," Transportation Research Record Journal of the Transportation Research Board, vol. 2319, pp. 77-85, 2012.

[23] M. Mahlawat, S. Rayan, S. Kuchangi, S. Patil, and M. W. burris, "Examination of student travel mode choice," in Proceedings of the Transportation Research Board 86th Annual Meeting, Washington, DC, USA, January 2007.

[24] J. Swait and J. Louviere, "The role of the scale parameter in the estimation and comparison of multinomial logit models," Journal of Marketing Research, pp. 305-314, 1993.

[25] T. Hägerstrand, "What about people in regional science?" Papers of the Regional Science Association, vol. 24, no. 1, pp. 6-21, 1970.

[26] K. M. N. Habib, "A random utility maximization (RUM) based dynamic activity scheduling model: application in weekend activity scheduling," Transportation, pp. 123-151, 2011. 